Research Paper

\title{
Laparoscopic Reconstructive Surgery is Superior to Vaginal Reconstruction in the Pelvic Organ Prolapse
}

\author{
Young-Han Park ${ }^{1}$, Seong Cheon Yang ${ }^{2}$, Sung Taek Park ${ }^{3}$, Sung Ho Park ${ }^{3}$, Hong Bae Kim ${ }^{3 凶}$ \\ 1. Department of Obstetrics and Gynecology, Hallym University Sacred Heart Hospital, Hallym University Medical Center (HUMC), \\ Seoul, Korea; \\ 2. Department of Obstetrics and Gynecology, Hankang Sacred Heart Hospital, Hallym University Medical Center (HUMC), Seoul, Korea; \\ 3. Department of Obstetrics and Gynecology, Kangnam Sacred Heart Hospital, Hallym University Medical Center (HUMC), Seoul, Korea.
}

$\triangle$ Corresponding author: Hong-bae Kim, Department of Obstetrics and Gynecology, Hallym University Medical Center (HUMC), Seoul, Korea. Address: Kangnam Sacred heart hospital,\#948-1, Dae-lim Dong, Yeoung-deungpo Ku, Seoul, Korea. E-mail:drhbkim@hallym.or.kr Fax: 82-2-849-4469 Tel: 82-2-829-5163.

(c) Ivyspring International Publisher. This is an open-access article distributed under the terms of the Creative Commons License (http://creativecommons.org/ licenses/by-nc-nd/3.0/). Reproduction is permitted for personal, noncommercial use, provided that the article is in whole, unmodified, and properly cited.

Received: 2014.03.06; Accepted: 2014.07.17; Published: 20I4.08.10

\begin{abstract}
Background: Our purpose was to provide the clinical advantages of the laparoscopic approach compare to the vaginal approach in correcting uterine and vaginal vault prolapse.

Methods: Between June 2007 and June 20II, 174 women were admitted to HUMC (Hallym University Medical Center) and underwent pelvic reconstructive surgery for prolapsed vaginal vault and uterus. Upon retrospective review of the medical records, 174 of the patients who had symptoms of pelvic organ prolapsed and Baden-Walker prolapse grade $\geq 2$ were selected and divided into two groups as follows: vaginal approach group $(n=120)$ and laparoscopic approach group $(n=54)$. We compared the results of clinical outcome by analyzing Student's $t$-test and $X^{2}$-test or the Fisher exact test as appropriate.

Results: There were significant difference in success rates without reoperation for recurrence as $91.7 \%$ (vaginal approach group, $n=110$ ) vs $100 \%$ (laparoscopic approach group, $n=54$ ), $p=0.032$. Mean follow-up duration was $31.3 \pm 7.6$ months for vaginal approach group and $29.7 \pm 9.7$ months for laparoscopic approach group. The Foley catheter indwelling duration $(4.7 \pm 1.9$ vs $3.4 \pm 2$. I days, $p<0.00 \mathrm{I})$ and the length of postoperative hospitalization $(6.4 \pm 2.1$ vs $5.0 \pm 1.9$ days, $p<0.00 \mathrm{I})$ were significantly longer in vaginal approach group, whereas the operative time was significantly longer (I08.2 \pm 38.6 vs $168.3 \pm 69.7$ minutes, $\mathrm{p}<0.001$ ) in laparoscopic approach group.

Conclusions: Our result suggest there is significantly lower recurrence rate requiring reoperation and less catheterization time but increased operative time for laparascopic sacrocolpopexy.
\end{abstract}

Key words: uterine vaginal vault prolapse, pelvic reconstructive surgery, laparoscopy.

\section{Introduction}

Pelvic organ prolapsed (POP) is the descent of one or more pelvic organs (uterus, vagina, bladder or bowels) through the defected vaginal wall by injury of supportive tissues. POP is a common problem as $50 \%$ of parous women experience [1]. The annual aggregated rate of associated surgery is 10 to 30 per 10,000 women [2]. Approximately 200,000 women undergo the surgery in the United States each year for POP [3,
4]. Genital prolapse is a highly prevalent disorder in women with a lifetime risk of surgical repair of $11.1 \%$ and is associated with stress urinary incontinence in $38 \%$ [5]. Growing life expectancy in society requires increased prolapse treatment because of increasing disease prevalence.

Upper vaginal prolapse (i.e. uterus, vaginal vault [after hysterectomy]) is one of the different types of 
POP. Incidence of vaginal vault prolapse is distributed widely between $0.2 \%$ and $43 \%$ [6]. Coexistent pelvic floor defects such as cystocele, rectocele or enterocele are frequently present in patients with prolapsed vaults $[7,8]$. Conservative managements with pessaries have limitations in many patients, so early correction by surgery appears to be more practical. Surgical approaches in managing the uterine and vaginal vault prolapse include the vaginal, abdominal, and recently, laparoscopic methods. Vaginal and uterine prolapse are conventionally treated vaginally by re-suspending the pelvic floor through attachment to several fixation points: the uterosacral, sacrotuberous, and sacrospinous ligaments [9]. The principal advantage of the vaginal approach is minimal morbidity. The abdominal approach includes uterosacral ligament suspension, sacrocolpopexy using intervening mesh, re-suspension of the vaginal vault to cooper's ligament. Benson et al. (1996) suggested that success rates with the abdominal approach are superior to those of the vaginal approach but at the cost of greater morbidity, longer hospitalization, and more postoperative pain [10]. Laparoscopic sacrocolpopexy was relatively recently introduced into the management of uterine and vaginal vault prolapse [11-14]. Laparoscopic approach has many advantages including better anatomic visibility as a result of magnification, insufflation, and improved hemostasis. Other advantages include shorter hospitalization, decreased postoperative pain, and better cosmeses of smaller incisions. There is some literature directly comparing different methods of surgical approaches (vaginal vs abdominal, and abdominal vs laparoscopic) $[10,15]$, but we could only find a few reports that directly compared the vaginal vs laparoscopic approach.

In this study, we aimed to demonstrate the results of retrospective case series comparing the laparoscopic approach with the vaginal approach in correcting POPs; especially regarding clinical outcomes.

\section{Materials and Methods}

\section{Study subjects}

Between June 2007 and June 2011, 174 women were admitted to HUMC (Hallym University Medical Center) and underwent pelvic reconstructive surgery for vaginal vault and uterine prolapse. We reviewed the medical records retrospectively. They had pelvic organ prolapse symptoms and were Baden-Walker halfway scoring system grade $\geq 2$ [8], and were selected and divided into two groups. 120 women were treated with vaginal approaches, and 54 women were treated with laparoscopic approaches. We compared the results with respect to demographic characteristics including perioperative parameters and success or recurrence rates. Hallym University Sacred Heart Hospital Institutional Review Board approved for this study (2011-I065).

\section{Perioperative assessment and data collection}

Before the surgery, every patient underwent an evaluation based on age, previous pelvic surgical history (hysterectomy, appendectomy, adnexectomy etc.), underlying medical problems (hypertension, diabetes, thyroid disorder etc.), parity, body mass index, vagino-perineal symptoms, urinary symptoms (dysuria, incontinence, frequency, etc.) and gastrointestinal symptoms (constipation).

Each patient underwent a pelvic examination in the same method. Pelvic examinations were performed with the patients in the dorsal lithotomy position under maximum straining (Valsalva maneuver) after emptying the bladder. The degree of POP was determined according to the Baden-Walker halfway scoring system.

In reviewing the medical records, we compared the demographic characteristics of the two groups, including perioperative parameters (operation time, hospitalization duration, Foley catheterization duration, estimated blood loss, hemoglobin change between pre-operative and post-operative 1st day, symptom changes etc.), and the success and recurrence ratios at 1-year follow up point.

\section{Surgical methods}

\section{Patient preparation}

The operative field was prepared and draped under general anesthesia with endotracheal intubation, and the patient was placed in a modified dorsal lithotomy position.

\section{Surgical procedures}

1) Vaginal approach group: Uterosacral ligament suspension, anterior colporrhaphy, posterior colporrhaphy were performed, and in cases of uterine prolapse, vaginal total hysterectomy was performed first.

A circumferential vaginal incision was made with blade around the cervix. Then, the bladder was gently dissected off from the uterus and the pouch of Douglas was opened. Ligations and cuts of ligaments and vessels were made with a reversed step of abdominal hysterectomy. When the peritoneal cavity was opened anteriorly, the round ligament was grasped, ligated and cut. A McCall culdoplasty with peritonization was performed and the vaginal cuff was closed using vicryls (\#1-0) in interrupted suture. Finally, anterior and posterior colporrhaphy was done as usual. 
2) Laparoscopic approach group: Sacrocolpopexy was performed, and in cases of uterine prolapse, laparoscopic total hysterectomy was performed first. Anterior colporrhaphy or posterior colporrhaphy were done as needed.

During laparoscopic surgery, 3 or 4 ports were used. The posterior peritoneum overlying the sacrum was incised medial to the ureter using a monopolar electrode, exposing longitudinal ligament covering the sacral promontory. Then the peritoneal incision was prolonged along the right pelvic wall up to the pouch of Douglas. A dilator was placed intravaginally to identify and mobilize the vaginal apex. The peritoneum was dissected from the vagina, with care taken to avoid injury to the bladder. The pouch of Douglas was incised between the left and right utero-sacral ligaments and the recto-vaginal space was dissected along the posterior vaginal wall. Polypropylene meshes (GYNECAREGYNEMESH ${ }^{\circledR P S}$, Ethicon ${ }^{\mathrm{TM}}$ ) were secured to the anterior and posterior vaginal wall respectively with \#0 Ethibond interrupted sutures. Meshes from the vagina were fixed to the longitudinal vertebral ligament with non-absorbable polyester \#0 suture (Ethibond ${ }^{\circledR}$, Ethi$\mathrm{con}^{\mathrm{TM}}$ ) or \#0 black silk suture in order to lift the prolapsed vaginal walls without tension. The operation was completed by reperitonealization.

\section{Statistical analysis}

Data were analyzed using Student's $t$-test and $\chi^{2}$ -test or the Fisher exact test as appropriate. When $p$-value was $<0.05$, it was considered as statistically significant.

\section{Results}

\section{I) Demographic characteristics of the two groups. (Table I)}

174 patients who had pelvic organ prolapse symptoms and were Baden-Walker prolapse grade $\geq$ 2 , underwent pelvic reconstructive surgery using the vaginal approach $(n=120)$ or laparoscopic approach $(n=54)$. Mean follow-up duration was $31.3 \pm 7.6$ months for vaginal approach group and $29.7 \pm 9.7$ months for laparoscopic approach group.

In terms of age, parity, BMI, prior pelvic surgery, medical history, frequency of Baden-Walker prolapse grade $\geq 2$, mean uterine and vaginal vault prolapse degree and combined POP, there were no significant differences between the two groups, except for the frequency of rectocele. Surgeries performed in vaginal approach group vs laparoscopic approach group were as follows: hysterectomy [114 (95.0 \%) vs 41 (75.9\%), $\mathrm{p}<0.001]$, uterosacral ligament suspension [98 (81.7\%) vs $0(0 \%), \mathrm{p}<0.001]$, anterior colporrhaphy [114 (95.0
$\%)$ vs $27(50.0 \%), \mathrm{p}<0.001]$, and posterior colporrhaphy [118 $(98.3 \%)$ vs $34(63.0 \%), p<0.001]$. Urinary frequency was significantly higher in vaginal approach group. Sacrocolpopexy performed frequency [0 $(0 \%)$ vs $32(100 \%), p<0.001]$ was significantly higher in laparoscopic approach group.

Table I. Demographic characteristics.

\begin{tabular}{|c|c|c|c|}
\hline & Vaginal $(n=120)$ & Lsc. $(n=54)$ & p-value \\
\hline Age ,yrs(mean $\pm \mathrm{SD})$ & $64.4 \pm 8.2$ & $66.9 \pm 9.6$ & 0.096 \\
\hline $\operatorname{Parity}($ mean $\pm \mathrm{SD})$ & $3.5 \pm 1.5$ & $3.5 \pm 1.8$ & 0.986 \\
\hline BMI, $\mathrm{Kg} / \mathrm{m}^{3}($ mean $\pm \mathrm{SD})$ & $24.5 \pm 3.1$ & $24.8 \pm 3.2$ & 0.620 \\
\hline Prior pelvic surgery, $\mathrm{n}(\%)$ & $34(28.3 \%)$ & $16(29.6 \%)$ & 0.861 \\
\hline \multicolumn{4}{|l|}{ Baden- Walker classification, $n(\%)$} \\
\hline 2 & $43(35.8 \%)$ & $12(22.2 \%)$ & 0.188 \\
\hline 3 & $62(51.7 \%)$ & $35(64.8 \%)$ & \\
\hline 4 & $15(12.5 \%)$ & $7(13.0 \%)$ & \\
\hline $\begin{array}{l}\text { Uterine prolapsed grade (mean } \pm \\
\text { SD) }\end{array}$ & $2.8 \pm 0.7$ & $2.9 \pm 0.6$ & 0.180 \\
\hline \multicolumn{4}{|l|}{ Combined POP, $n(\%)$} \\
\hline Uterine/vault prolapse & $120(100.0 \%)$ & $54(100.0 \%)$ & NA \\
\hline cystocele & $31(25.8 \%)$ & $14(25.9 \%)$ & 0.990 \\
\hline rectocele & $25(20.8 \%)$ & $17(31.5 \%)$ & 0.129 \\
\hline \multicolumn{4}{|l|}{$\begin{array}{l}\text { Surgeries performed in each group, } \\
\mathbf{n}(\%)\end{array}$} \\
\hline Hysterectomy & $114(95.0 \%)$ & $41(75.9 \%)$ & $<0.001$ a \\
\hline Sacrocolpopexy & $0(0.0 \%)$ & $54(100.0 \%)$ & $<0.001$ a \\
\hline Uterosacral suspension & $98(81.7 \%)$ & $0(0.0 \%)$ & $<0.001$ a \\
\hline Anterior colporrhaphy & $114(95.0 \%)$ & $27(50.0 \%)$ & $<0.001$ a \\
\hline Posterior colporrhaphy & $118(98.3 \%)$ & $34(63.0 \%)$ & $<0.001$ a \\
\hline Anti-incontinence surgery & $1(0.8 \%)$ & $2(3.7 \%)$ & $0.228^{b}$ \\
\hline $\mathrm{F} / \mathrm{U}$ duration, months $($ mean $\pm \mathrm{SD})$ & $31.3 \pm 7.6$ & $29.7 \pm 9.7$ & 0.251 \\
\hline
\end{tabular}

\section{2) Postoperative clinical outcomes. (Table 2)}

In terms of hemoglobin $(\mathrm{Hb})$ change, febrile morbidity and estimated blood loss, vaginal approach group and laparoscopic approach group did not show any statistically significant differences. There were no cases of conversion to laparotomy and transfusion during operations. Foley catheterization duration $(4.7 \pm 1.9$ vs $3.4 \pm 2.1$ days, $p=0.001)$ was significantly longer in vaginal approach group. The rate of Foley catheter duration $>5$ days (33 [27.5\%] vs 4 [7.4\%] days, $p=0.003$ ) was higher in vaginal approach group. Operation time was significantly longer in laparoscopic approach group [108.2 \pm 38.6 vs $168.3 \pm 69.7$ minutes, $\mathrm{p}<0.001]$. Postoperative hospitalization duration was significantly shorter in laparoscopic approach group [6.4 \pm 2.1 vs $5.0 \pm 1.9$ days, $\mathrm{p}<0.001]$.

\section{3) Perioperative symptom changes. (Table 3)}

The frequency of vagino-perineal symptoms (pressure) were $118 \% \quad(\mathrm{n}=98.3$, vaginal approach group), $96.3 \%(n=52$, laparoscopic approach group) pre-operatively which remained in $5.0 \%(\mathrm{n}=6$, vaginal approach group) and $5.6 \%(n=3$, laparoscopic ap- 
proach group) post-operatively. Urinary problems (urgency, dysuria, incontinence etc.) was $35.8 \%$ (vaginal approach group, $\mathrm{n}=43$ ), $24.1 \%$ (laparoscopic approach group, $n=13$ ) preoperatively which remained in $5.0 \%(n=6$, vaginal approach group) and $3.7 \%(n=2$, laparoscopic approach group) postoperatively. Gastrointestinal (GI) problems were present at $3.1 \%$ in laparoscopic approach group $(n=1)$ but disappeared post-operatively. There were no cases of GI problems in vaginal approach group peri-operatively. Peri-operative symptom changes in two groups did not show any statistically significant differences.

Table 2. Clinical outcomes of two groups.

\begin{tabular}{|c|c|c|c|}
\hline & $\begin{array}{l}\text { Vaginal } \\
\text { Approach } \\
(\mathrm{n}=120)\end{array}$ & $\begin{array}{l}\text { Lsc ap- } \\
\text { proach } \\
(\mathrm{n}=54)\end{array}$ & p-value \\
\hline $\begin{array}{l}\text { Hemoglobin change, gm/dL (mean } \pm \\
\text { SD) }\end{array}$ & $1.4 \pm 0.9$ & $1.5 \pm 0.9$ & 0.924 \\
\hline No. of women transfused, $\mathrm{n}(\%)$ & $0(0 \%)$ & $0(0 \%)$ & NA \\
\hline Catheter duration, day (mean $\pm \mathrm{SD}$ ) & $4.7 \pm 1.9$ & $3.4 \pm 2.1$ & $<0.001^{a}$ \\
\hline Catheter duration $>5$ days , $\mathrm{n}(\%)$ & $33(27.5 \%)$ & $4(7.4 \%)$ & 0.003 a \\
\hline Febrile morbidity, $\mathrm{n}(\%)$ & $4(3.3 \%)$ & $4(7.4 \%)$ & $0.256^{b}$ \\
\hline Operation time, $\min ($ mean \pm SD) & $108.2 \pm 38.6$ & $168.3 \pm 69.7$ & $<0.001^{a}$ \\
\hline Post-op. hospital stay, day (mean \pm SD) & $6.4 \pm 2.1$ & $5.0 \pm 1.9$ & $<0.001$ a \\
\hline Estimated blood loss, $\mathrm{ml}($ mean $\pm \mathrm{SD})$ & $285.6 \pm 130.7$ & $315.8 \pm 99.6$ & 0.098 \\
\hline Conversion to laparotomy, $\mathrm{n}(\%)$ & $0(0 \%)$ & $0(0 \%)$ & NA \\
\hline
\end{tabular}

Table 3. Peri-operative symptom changes.

\begin{tabular}{lllllll}
\hline & pre-op & & p-value & post-op & p-value \\
\cline { 2 - 7 } & $\begin{array}{l}\text { Vaginal } \\
(\mathrm{n}=120)\end{array}$ & Lsc. $(\mathrm{n}=54)$ & p-value & $\begin{array}{l}\text { Vaginal } \\
(\mathrm{n}=120)\end{array}$ & $\begin{array}{l}\text { Lsc. } \\
(\mathrm{n}=54)\end{array}$ & p-value \\
\hline VPS, n(\%) & $118(98.3 \%)$ & $52(96.3 \%)$ & 0.589 a & $6(5.0 \%)$ & $3(5.6 \%)$ & 1.000 a \\
Urinary, & $43(35.8 \%)$ & $13(24.1 \%)$ & 0.125 & $6(5.0 \%)$ & $2(3.7 \%)$ & 1.000 a \\
n(\%) & & & & & & \\
GI, n(\%) & $0(0.0 \%)$ & $1(1.9 \%)$ & 0.310 a & $0(0.0 \%)$ & $0(0.0 \%)$ & NA \\
\hline
\end{tabular}

Vaginal: vaginal approach, Lsc: laparoscopic approach, pre-op: pre-operation, VPS: Vaginal-perineal symptom, post-op: post-operation, NA: not applicable, a Fisher's exact test.

\section{4) Postoperative wound complications during follow up. (Table 4)}

There were no significant differences in post-operative wound complications between vaginal approach group and laparoscopic approach group $(p=0.75)$. Three cases of wound infection $(2.5 \%)$, one case of disruption $(0.8 \%)$, and one case of hematoma $(0.8 \%)$ occurred in vaginal approach group, whereas three cases of mesh erosion $(5.8 \%)$ were present in laparoscopic approach group.

\section{5) Recurrence of pelvic organ prolapses during follow-up. (Table 5)}

Recurrence was defined as pelvic organ prolapse grade $\geq 1$. Recurrence requiring reoperation was defined as symptomatic pelvic organ prolapse grade $\geq 2$.
Success was defined when there were no evidences of pelvic organ prolapse or pelvic organ prolapsed grade scored I by pelvic examination. There were a total of 11 cases of recurrence including three cases of cystocele $(27.27 \%)$, four cases of vaginal vault recurrences $(36.36 \%)$ and one case with rectocele recurrence $(9.1$ $\%$ ) where 10 of these 11 cases (90.9\%) needed reoperation. No case of recurrence was encountered in laparoscopic approach patients.

Thus the success rate was significantly higher in laparoscopic approach patients [(91.7 \% (vaginal approach patients) vs $100 \%$ (laparoscopic approach patients $)](p=0.032)$.

Table 4. Post-operative wound complications during follow-up showed no significant differences.

\begin{tabular}{llll}
$\begin{array}{l}\text { Wound complication, } \\
\mathrm{n}(\%)\end{array}$ & $\begin{array}{l}\text { Vaginal approach } \\
(\mathrm{n}=120)\end{array}$ & $\begin{array}{l}\text { Lsc approach } \\
(\mathrm{n}=54)\end{array}$ & p-value \\
\hline Infection, & $3(2.5 \%)$ & $0(0.0 \%)$ & \\
Hematoma & $1(0.8 \%)$ & $0(0.0 \%)$ & \\
Disruption & $1(0.8 \%)$ & $0(0.0 \%)$ & \\
Mesh erosion & $0(0.0 \%)$ & $3(5.8 \%)$ & 0.705 a \\
Total & $5(4.2 \%)$ & $3(5.6 \%)$ & \\
\hline
\end{tabular}

Table 5. Recurrence of pelvic organ prolapse during follow-up showed no significant difference.

\begin{tabular}{|c|c|c|c|c|c|c|}
\hline \multirow{2}{*}{$\begin{array}{c}\text { Part of } \\
\text { recurrence } \\
\mathrm{n}(\%)\end{array}$} & \multicolumn{2}{|c|}{ Recurrence } & \multirow{2}{*}{$\begin{array}{l}\text { p-value } \\
\text { p-value }\end{array}$} & \multicolumn{2}{|c|}{$\begin{array}{l}\text { Requiring reopera- } \\
\text { tion }\end{array}$} & \multirow{2}{*}{$\begin{array}{l}\mathrm{p} \text {-value } \\
\text { p-value }\end{array}$} \\
\hline & $\begin{array}{l}\text { Vaginal } \\
(\mathrm{n}=120)\end{array}$ & Lsc. $(n=54)$ & & $\begin{array}{l}\text { Vaginal } \\
(\mathrm{n}=120)\end{array}$ & $\begin{array}{l}\text { Lsc. } \\
(\mathrm{n}=54)\end{array}$ & \\
\hline Cystocele & $4(3.3 \%)$ & $0(0.0 \%)$ & & $3(2.5 \%)$ & $0(0.0 \%)$ & \\
\hline VVP & $4(3.3 \%)$ & $0(0.0 \%)$ & & $4(3.3 \%)$ & $0(0.0 \%)$ & \\
\hline Rectocele & $3(2.5 \%)$ & $0(0.0 \%)$ & & $3(2.5 \%)$ & $0(0.0 \%)$ & \\
\hline Total & $11(9.2 \%)$ & $0(0.0 \%)$ & $0.019 \mathrm{a}$ & $10(8.3 \%)$ & $0(0.0 \%)$ & $0.032^{\mathrm{a}}$ \\
\hline $\begin{array}{l}\text { Success } \\
\text { rate: }\end{array}$ & $110(91.7 \%)$ & $54(100.0 \%)$ & $\mathrm{P}=0.032 \mathrm{a}$ & & & \\
\hline
\end{tabular}

\section{Comments}

As mean life expectancy grows longer, needs for management of POP, including uterine and vaginal vault prolapse, will increase. There are different types of reconstructive surgery for POP, including vaginal, abdominal, and laparoscopic approaches. In this study, we tried to compare the clinical outcomes of the laparoscopic approach with that of the vaginal approach in correcting uterine and vaginal vault prolapse.

DeLancey (1992) reported that level one support is sacrificed as often as $45 \%$ of the time after hysterectomy [16]. Failure to reattach the cardinal-uterosacral ligament complex adequately to the pubocervical fascia and rectovaginal fascia at the 
vaginal cuff during hysterectomy is proposed to be the most common cause of vaginal vault prolapsed [17]. As knowledge of the causes of vaginal vault prolapse and anatomy of the pelvic floor increased, restoration of the cardinal-uterosacral ligament support mechanism, and also reconstructive effort toward the re-approximation of the pubo-cervical and recto-vaginal fascia began to be performed [18].

In cases of uterine prolapse, suspending the vaginal stump after hysterectomy is commonly accepted as the usual method. In this study, we performed hysterectomy first followed by reconstructive surgery. Utero-sacral ligament suspensions were performed in vaginal reconstructive surgeries [19], whereas sacral colpopexies using separate meshes were done in laparoscopic reconstructive surgeries. Sacral colpopexy restored the apical support by anchoring the mesh to the anterior and posterior vaginal walls caudally and to the longitudinal ligament covering the sacral promontory.

\section{Operation time}

Mean operation time was significantly shorter in vaginal approach group. But mean operation time in laparoscopic approach group was also within the acceptable range and it was relatively shorter than that of other reports [10-14]. Although laparoscopic surgery requires a longer operation time than other approaches, when compared with the abdominal approach, it has the advantages of low postoperative morbidity, less postoperative pain, better cosmeses, and a shorter hospitalization duration that may offset this disadvantage [10].

\section{Hospitalization time}

Post-operative hospitalization duration was longer in vaginal approach group than the other group. This may be related to significantly higher frequencies of vaginal wall dissection for anterior and posterior colporrhaphies in vaginal approach group than in the laparoscopic approach group. Additionally, a relation to the significantly longer duration of Foley catheterization in vaginal approach group can be suspected. Further study will be necessary.

\section{Postoperative clinical manifestations}

In terms of perioperative symptom changes, uterine and vaginal prolapse related vaginal-perineal symptoms and gastrointestinal problem were well controlled in both groups. The urinary problems were also well controlled, but newly developed problems were encountered post-operatively in some cases of both groups. Possible causes of newly developed urinary problems after reconstructive surgery for POP are as follows: large cystocele, heavy bleeding during operation, levator plication, Kelly plication, etc.
Hakvoort (2009) described these as possibilities for increased risk of urinary dysfunction [20].

\section{Mesh induced complications}

Mesh may also cause de novo urinary incontinence. It was suggested that the incidence is higher in cases of augmentation of the anterior vaginal wall with mesh than with vaginal vault prolapsed [21-23]. In this study, mesh was not used for anterior colporrhaphies, and the incidence of urinary dysfunction was relatively low. Using the mesh for the vaginal apical support, the rate of mesh erosion was between $3.4 \%$ and $16 \%$ [24-27]. De Tayrac R (2006) reported that the use of a low-weight, monofilament, large-pore size polypropylene mesh coated with a hydrophilic film for vaginal prolapse repairs was associated with a $10 \%$ erosion rate when concomitant hysterectomy or trachelectomy was performed, and with a $4 \%$ erosion rate if the uterus was preserved or if the procedure was performed after a previous hysterectomy [28]. Risk factors of mesh erosion are the age of patient, estrogen deficiency, type and size of synthetic mesh, surgical approach, method of fixation, and combined operation [29-31]. It is suggested that mesh erosion is usually predisposed to cause marked scarring and thinning of the vagina from previous vaginal repairs or a combined abdominal hysterectomy and sacral colpopexy. This problem can be eliminated by the use of donor fascia lata or a xenograft [32]. Whereas, in other reports, it is suggested that preservation of the uterus may act as a shock absorber and lead to a reduced risk of mesh erosion $[12,33]$. In this study, two cases of mesh erosion occurred in the laparoscopic approaches and both of the erosion cases underwent concurrent hysterectomy. After the removal of exposed portion of mesh, the vaginal vault suspension effect was maintained in one case. The other case was successfully treated for infection control with antibiotic therapy for 20 days only.

\section{Relapse}

During the follow-up period, relapses were encountered only in vaginal approach group. This leads us to suspect that the use of mesh for vaginal apex suspension in laparoscopic approach group is mechanically stronger than the patient's own tissues. Site-specific repairs and uterosacral ligament-vaginal vault suspensions performed without mesh are dependent on the integrity of the endopelvic fascia lining the pelvic floor. This tissue has frequently become attenuated, suffering the injurious effects of long-standing prolapsed [15]. Reliance on these fibro-muscular structures may jeopardize the long-term success of surgeries [34]. Another causative mecha- 
nism that might be related with relapse mainly in the vaginal approach is neuropathy. There could be a possible relationship of vaginal wall dissection relating neuropathy with relapse $[35,36]$. The neuropathy may have an effect on subsequent muscle strength and the integrity of muscular tissue support. In this study, relapse was only encountered in vaginal approach group. This could be explained by neuropathy because anterior and posterior colporrhaphies with vaginal dissection were significantly more frequent in vaginal approach group than in laparoscopic approach group. Foley catheter duration was more prolonged in vaginal approach group and might also lead to prolongation of hospital duration. Thus, vaginal dissection and related neuropathy may also be related to lower urinary dysfunction after reconstructive surgery. But this relationship remains to be determined.

\section{Success rate}

The success rate of the vaginal approach has been reported to be between $87 \%$ and $100 \%$ [19,37-40], whereas that of the laparoscopic approach is between $79 \%$ and $100 \%[10,12,13,15,41,42]$. The success rate in this study was higher in laparoscopic approach group than in vaginal approach group as $100 \%$ vs $91.7 \%$ respectively, $\mathrm{p}=0.032$. Our success rates in both groups were relatively high and well within the acceptable range but laparoscopic approach appeared superior.

Vaginal and uterine prolapse are conventionally treated vaginally by re-suspending the pelvic floor through attachment to various fixation points, but laparoscopic treatment has been relatively recently introduced into the management armamentarium of the vaginal vault. Most publications on laparoscopic surgeries consist of comparatively small patient populations with short follow-ups, with 12 months for the shortest. This study may also have certain limitations, where prolongation of the follow-up period may be able to detect new relapses..

\section{Conclusion}

This is a report comparing the laparoscopic approach with the vaginal approach in reconstructive surgery for uterine and vaginal vault prolapse. There were several limitations to our study. This study was a preliminary one and was designed as a retrospective study. The size of population was not large enough. In the future, randomized, long term prospective clinical studies of a larger scale will be necessary to determine the superiority of approaches, along with the introduction of objective tools to evaluate urinary problems, gastrointestinal problems, and sexual function.

Although operation time was longer in laparo- scopic approach group, it was well within the acceptable range. The laparoscopic approach led to superior success rate, shorter hospitalization and shorter Foley catheter duration compare to the vaginal approach. Therefore we disclosed laparoscopic surgery is more advantageous than vaginal surgery, but at the cost of longer operation times.

\section{Conflict of Interest}

The authors have declared that no conflicts of interest exist.

\section{References}

1. Beck RP, McCormick S, Nordstrom L. A 25-year experience with 519 anterior colporrhaphy procedures. Obstet Gynecol. 1991 Dec;78(6):1011-8.

2. Brubaker L, Nygaard I, Richter HE, Visco A, Weber AM, Cundiff GW, et al. Two-year outcomes after sacrocolpopexy with and without burch to prevent stress urinary incontinence. Obstet Gynecol. 2008 Jul;112(1):49-55.

3. Boyles SH, Weber AM, Meyn L. Procedures for pelvic organ prolapse in the united states, 1979-1997. Am J Obstet Gynecol. 2003 Jan;188(1):108-15.

4. Subak LL, Waetjen LE, van den Eeden S, Thom DH, Vittinghoff E, Brown JS. Cost of pelvic organ prolapse surgery in the united states. Obstet Gynecol. 2001 Oct;98(4):646-51.

5. Olsen AL, Smith VJ, Bergstrom JO, Colling JC, Clark AL. Epidemiology of surgically managed pelvic organ prolapse and urinary incontinence. Obstet Gynecol. 1997 Apr;89(4):501-6.

6. Higgs PJ, Chua HL, Smith AR. Long term review of laparoscopic sacrocolpopexy. BJOG. 2005 Aug;112(8):1134-8.

7. Sederl J. Zur operation des prolapses der blind endigenden sheiden. Geburtshilfe Frauenheilkd. 1958;18:824-8.

8. Baden WB, Walker T. Surgical repair of vaginal defects. Philadelphia: JB Lippincott; 1992: 183-94.

9. Flynn BJ, Webster GD. Surgical management of the apical vaginal defect. Curr Opin Urol. 2002 Jul;12(4):353-8.

10. Benson JT, Lucente V, McClellan E. Vaginal versus abdominal reconstructive surgery for the treatment of pelvic support defects: A prospective randomized study with long-term outcome evaluation. Am J Obstet Gynecol. 1996 Dec;175(6):1418,21; discussion 1421-2.

11. Dubuisson JB, Jacob S, Chapron C, Fauconnier A, Decuypere F, Dubernard G. Laparoscopic treatment of genital prolapse: Lateral utero-vaginal suspension with 2 meshes. results of a series of 47 patients]. Gynecol Obstet Fertil. 2002 Feb;30(2):114-20.

12. Gadonneix P, Ercoli A, Salet-Lizee D, Cotelle O, Bolner B, Van Den Akker M, et al. Laparoscopic sacrocolpopexy with two separate meshes along the anterior and posterior vaginal walls for multicompartment pelvic organ prolapse. J Am Assoc Gynecol Laparosc. 2004 Feb;11(1):29-35.

13. Nezhat $\mathrm{CH}$, Nezhat F, Nezhat $\mathrm{C}$. Laparoscopic sacral colpopexy for vaginal vault prolapse. Obstet Gynecol. 1994 Nov;84(5):885-8.

14. Rozet F, Mandron E, Arroyo C, Andrews H, Cathelineau X, Mombet A, et al. Laparoscopic sacral colpopexy approach for genito-urinary prolapse: Experience with 363 cases. Eur Urol. 2005 Feb;47(2):230-6.

15. Hsiao KC, Latchamsetty K, Govier FE, Kozlowski P, Kobashi KC. Comparison of laparoscopic and abdominal sacrocolpopexy for the treatment of vaginal vault prolapse. J Endourol. 2007 Aug;21(8):926-30.

16. DeLancey JO. Anatomic aspects of vaginal eversion after hysterectomy. Am J Obstet Gynecol. 1992 Jun;166(6 Pt 1):1717,24; discussion 1724-8.

17. Miklos JR, Moore RD, Kohli N. Laparoscopic surgery for pelvic support defects. Curr Opin Obstet Gynecol. 2002 Aug;14(4):387-95.

18. Richardson AC, Lyon JB, Williams NL. A new look at pelvic relaxation. Am J Obstet Gynecol. 1976 Nov 1;126(5):568-73.

19. Shull BL, Bachofen C, Coates KW, Kuehl TJ. A transvaginal approach to repair of apical and other associated sites of pelvic organ prolapse with uterosacral ligaments. Am J Obstet Gynecol. 2000 Dec;183(6):1365,73; discussion 1373-4.

20. Hakvoort RA, Dijkgraaf MG, Burger MP, Emanuel MH, Roovers JP. Predicting short-term urinary retention after vaginal prolapse surgery. Neurourol Urodyn. 2009;28(3):225-8.

21. Dietz HP, Vancaillie P, Svehla M, Walsh W, Steensma AB, Vancaillie TG. Mechanical properties of urogynecologic implant materials. Int Urogynecol J Pelvic Floor Dysfunct. 2003 Oct;14(4):239,43; discussion 243.

22. Elneil S, Cutner AS, Remy M, Leather AT, Toozs-Hobson P, Wise B. Abdominal sacrocolpopexy for vault prolapse without burial of mesh: A case series. BJOG. $2005 \mathrm{Apr} ; 112(4): 486-9$.

23. Hiltunen R, Nieminen K, Takala T, Heiskanen E, Merikari M, Niemi K, et al. Low-weight polypropylene mesh for anterior vaginal wall prolapse: A randomized controlled trial. Obstet Gynecol. 2007 Aug;110(2 Pt 2):455-62.

24. Iglesia CB, Fenner DE, Brubaker L. The use of mesh in gynecologic surgery. Int Urogynecol J Pelvic Floor Dysfunct. 1997;8(2):105-15. 
25. Kohli N, Walsh PM, Roat TW, Karram MM. Mesh erosion after abdominal sacrocolpopexy. Obstet Gynecol. 1998 Dec;92(6):999-1004.

26. Nygaard IE, McCreery R, Brubaker L, Connolly A, Cundiff G, Weber AM, et al. Abdominal sacrocolpopexy: A comprehensive review. Obstet Gynecol. 2004 Oct; 104(4):805-23.

27. Valaitis SR, Stanton SL. Sacrocolpopexy: A retrospective study of a clinician's experience. Br J Obstet Gynaecol. 1994 Jun;101(6):518-22.

28. de Tayrac R, Picone O, Chauveaud-Lambling A, Fernandez H. A 2-year anatomical and functional assessment of transvaginal rectocele repair using a polypropylene mesh. Int Urogynecol J Pelvic Floor Dysfunct. 2006 Feb;17(2):100-5.

29. Birch C, Fynes MM. The role of synthetic and biological prostheses in reconstructive pelvic floor surgery. Curr Opin Obstet Gynecol. 2002 Oct;14(5):527-35.

30. Mistrangelo E, Mancuso S, Nadalini C, Lijoi D, Costantini S. Rising use of synthetic mesh in transvaginal pelvic reconstructive surgery: A review of the risk of vaginal erosion. J Minim Invasive Gynecol. 2007;14(5):564-9.

31. Visco AG, Weidner AC, Barber MD, Myers ER, Cundiff GW, Bump RC, et al. Vaginal mesh erosion after abdominal sacral colpopexy. Am J Obstet Gynecol. 2001 Feb;184(3):297-302.

32. Uzoma A, Farag KA. Vaginal vault prolapse. Obstet Gynecol Int. 2009;2009:275621.

33. Cosson M, Rajabally R, Bogaert E, Querleu D, Crepin G. Laparoscopic sacrocolpopexy, hysterectomy, and burch colposuspension: Feasibility and short-term complications of 77 procedures. JSLS. 2002;6(2):115-9.

34. Miklos JR, Kohli N, Lucente V, Saye WB. Site-specific fascial defects in the diagnosis and surgical management of enterocele. Am J Obstet Gynecol. 1998 Dec;179(6 Pt 1):1418,22; discussion 1822-3.

35. Smith AR, Hosker GL, Warrell DW. The role of partial denervation of the pelvic floor in the aetiology of genitourinary prolapse and stress incontinence of urine. A neurophysiological study. Br J Obstet Gynaecol. 1989 Jan;96(1):24-8

36. Benson JT, McClellan E. The effect of vaginal dissection on the pudendal nerve. Obstet Gynecol. 1993 Sep;82(3):387-9.

37. Jenkins $V R, 2 n d$. Uterosacral ligament fixation for vaginal vault suspension in uterine and vaginal vault prolapse. Am J Obstet Gynecol. 1997 Dec;177(6):1337,43; discussion 1343-4

38. Karram M, Goldwasser S, Kleeman S, Steele A, Vassallo B, Walsh P. High uterosacral vaginal vault suspension with fascial reconstruction for vaginal repair of enterocele and vaginal vault prolapse. Am J Obstet Gynecol. 2001 Dec;185(6):1339,42; discussion 1342-3.

39. Barber MD, Visco AG, Weidner AC, Amundsen CL, Bump RC. Bilateral uterosacral ligament vaginal vault suspension with site-specific endopelvic fascia defect repair for treatment of pelvic organ prolapse. Am J Obstet Gynecol. 2000 Dec;183(6):1402,10; discussion 1410-1.

40. Amundsen CL, Flynn BJ, Webster GD. Anatomical correction of vaginal vault prolapse by uterosacral ligament fixation in women who also require a pubovaginal sling. J Urol. 2003 May;169(5):1770-4.

41. Cosson M, Bogaert E, Narducci F, Querleu D, Crepin G. Laparoscopic sacral colpopexy: Short-term results and complications in 83 patients]. J Gynecol Obstet Biol Reprod (Paris). 2000 Dec;29(8):746-50.

42. Ross JW. Techniques of laparoscopic repair of total vault eversion after hysterectomy. J Am Assoc Gynecol Laparosc. 1997 Feb;4(2):173-83. 